\title{
Reasons for and Developments in International Scientific Collaboration: Does an Asia-Pacific Research Area Exist from a Bibliometric Point of View?
}

\author{
Stefanie Haustein ${ }^{a}$, Dirk Tunger ${ }^{a, \star}$, Gerold Heinrichs $^{b}$ and Gesa Baelz ${ }^{b}$ \\ ${ }^{a}$ Forschungszentrum Jülich, Central Library, 52428 Jülich, Germany \\ \{s.haustein, d.tunger\}@fz-juelich.de \\ ${ }^{\mathrm{b}}$ International Bureau of the Federal Ministry of Education and Research, \\ Heinrich-Konen-Str. 1, 53227 Bonn, Germany \\ \{gerold.heinrichs, gesa.baelz\}@dlr.de \\ * corresponding author
}

\begin{abstract}
This paper describes the different forms of and tries to give reasons for international scientific collaboration in general. It focuses on eleven countries in the Asia-Pacific region by evaluating their national research output with the help of bibliometric indicators in particular. Over two million journal articles published by these countries between 1998 and 2007 in ISIlisted periodicals are analyzed. Discipline-specific publication and citation profiles reveal national strengths and weaknesses in the different research domains. The exponential increase in publication output by China over the last few years is astonishing, but in terms of visibility, i.e. citation rates, China cannot keep up with leading science nations, remaining below the world average. A discipline-specific analysis shows that Chinese authors took an active part in more than a quarter of all articles and reviews published in the field of materials science in 2007, while their contribution to medical research is very low. Co-publication networks among the eleven countries are generated to observe the development of cooperation bonds in the region. Applying Salton's measure of international collaboration strength, an above-average strengthening of scientific collaboration in the Asia-Pacific region can be observed.
\end{abstract}

\section{Introduction}

This paper focuses on the analysis of the scientific output and collaboration of eleven countries in the Asia-Pacific region and addresses the different aspects of international collaboration in science in general. The underlying analysis was conducted on behalf of the International Bureau of the German Federal Ministry of Education and Research (BMBF) in 2008 (Haustein, Mittermaier \& Tunger, 2008; Heinrichs, Baelz, Haustein \& Tunger, to be 
published). The International Bureau was interested in the publication behavior of and among countries in the Asia-Pacific region, which were regarded as current or upcoming research nations: Australia, China, Indonesia, Japan, Malaysia, New Zealand, Singapore, South Korea, Taiwan, Thailand and Vietnam ${ }^{1}$. A comparison with Germany should help us gain more information on science and research in these countries, possibly find partners for future cooperation, adjust funding decisions, and derive concepts for future collaboration in science and technology. The study is based on data from Thomson Reuters' SCI-Expanded, SSCl and $\mathrm{A} \& \mathrm{HCl}$, which were accessed through the Web of Science (WoS) in July 2008. The publication output on the country level was examined for the period of 1992 to 2007, whereas the detailed analysis focuses on the ten years from 1998 to 2007. Additionally, data analysis for this paper was conducted in April 2009. In 2002, Moed expressed the need on the part of science managers for output studies on R\&D activities as follows:

Science and technology are the driving forces of our contemporary society. Analyses of these forces are indispensable in any national science policy or research management strategy. In view of this there is a need for valid and user-oriented analyses of scientific and technological developments.

Furthermore, the importance of research evaluation was emphasized as follows:

The ability to judge a nation's scientific standing is vital for the governments, business and trusts that must decide scientific priorities and funding. (King, 2004)

This paper aims to outline the different approaches for analyzing research output on a national level and to explain the different forms of and give reasons for international collaboration. The theoretical approach shall be supported by examples from the study of the eleven countries in the Asia-Pacific region. Since a "greater intra-regional collaboration" (Kim, 2005) has been attested to Asia before, this paper will focus on the question as to whether patterns of collaboration indicate the existence of an Asia-Pacific research area from a bibliometric point of view.

\section{Country studies}

Studies concerning the scientific output of countries may focus on the research output of a nation as a whole, analyze a country's publication or science activity profile, the impact of its research in different areas or highlight the major institutions or authors involved (Gómez \& Méndez 1992; Gupta, Munshi \& Mishra, 2004; Tunger, 2009). Time analyses will also reveal the development of different areas of research or show the changes in a country's publication profile over the last few years (Okubo, Dore, Ojasoo \& Miquel, 1998). Considering indicators such as a country's expenditure on R\&D, the number of researchers or population size and gross domestic product (GDP), relates the scientific output of a country to its input and allows comparisons between countries of different sizes (Kim, 2005; King, 2004). 
Figure 1a Number of Publications of Australia, China, Japan, South Korea and Taiwan in Journals covered by ISI from 1992 to 2007.

Figure 1b Number of Publications of Indonesia, Malaysia, New Zealand, Singapore, Thailand and Vietnam in Journals covered by ISI from 1992 to 2007.

Similar to the worldwide trend in publications, an increase in publication output was also observed for the countries in the Asia-Pacific region in the period of 1992 to 2007 . The annual number of publications of each of the eleven countries is shown in figures $1 \mathrm{a}$ and $1 \mathrm{~b}$. The huge differences in annual publication output required the splitting of the diagram. These differences have to be taken into consideration when interpreting the results of the study. The majority of these countries produce a level of publications that currently ranges between a few hundred to around 10,000 per annum. Five countries in this group distinguish themselves from the others in that they partially exhibit significantly higher outputs. These include Taiwan, South Korea, Australia, Japan, and China (see figure 1a). The increase in publications by China is particularly striking and has been observed elsewhere (Glanzel, Debackere \& Meyer, 2008; Martinez \& Moore, 2008). Its growth is exponential ( $y=4 \mathrm{E}$ $143 \mathrm{e}^{0.1692 x}$ with $\mathrm{R}^{2}=0.99$ ) and leaves all of the other research nations, even established scientific powerhouses like Japan and Australia, trailing behind.

If this trend continues, China will soon become the world's second largest producer of scientific knowledge behind the USA. (Glanzel, Debackere \& Meyer, 2008)

In the 1970s, China was still practically non-existent in terms of publication output in international journals (Frame, Narin \& Carpenter, 1977). It started off with around 9,300 publications in 1992, which was far less than Australia. In 2007, however, China boasted almost 100,000 publications, which saw it pass out established research nations such as Japan, which can be compared to Germany in terms of publication output during the years analyzed. Even though China's growth rates are astonishing, it is still far from drawing level with the USA or EU-27, which published approximately 450,000 and 502,000 papers, respectively, in ISI-listed journals in 2007. In addition to China, South Korea also increased its output from 2,600 to 33,800 between 1992 and 2007. With an almost six-fold increase in scientific output, Thailand and Singapore also produced very high growth rates. Of course, this is due to the above-mentioned difference in volume: only a fairly low number of publications at the outset in 1992 allow for these astonishing growth rates.

To create country-specific publication profiles, the output in this study has not only been analyzed on a country level, but a country's publications also have been assigned to different research areas. Due to the differences in publication and citation behavior in specific fields of science, citation and publication rates cannot be compared between different research areas (King, 2004). Thus, publications were allocated to one of thirteen different disciplines by an intellectual topic classification according to the ISI subject category of the journal they were 
published in. Due to multiple classification of journals, articles were counted more than once if they belonged to subject categories that were assigned to more than one of the thirteen disciplines. The thirteen disciplines are agricultural science, biology and biotechnology, chemistry, energy, engineering, geosciences, information and computer science, materials science, mathematics, medicine, multidisciplinary journals, nanotechnology, and physics. The database share of articles and reviews published in these thirteen disciplines for 2007 is shown in figure 2 . Since the disciplines are not represented equally in the database and due to different publication and citation behavior, the publication profiles of the countries (figures

Figure 2 Share of Articles and Reviews published in 2007 in SCI EXPANDED, SSCl and A\&HCl according to thirteen scientific Disciplines. Papers may have been assigned to more than one Discipline.

$3 a$ and $3 b$ ) are normalized with respect to the total output in each field in 2007. Figure $3 a$ clearly shows China's domination among the Asia-Pacific countries in terms of output. In 2007, Chinese researchers produced over a quarter of worldwide publications in materials science and a fifth of the output in chemistry and nanotechnology. In medicine, the dominant research field in the database, however, China trails behind.

Figure 3a Publication Profiles for Australia, China, Japan, South Korea and Taiwan (Research and Review Articles only). Country Output is relativized with respect to the total Output in the specific Research Discipline.

Figure 3b Publication Profiles for Indonesia, Malaysia, New Zealand, Singapore, Thailand and Vietnam (Research and Review Articles only). Country Output is relativized with respect to the total Output in the specific Research Discipline.

The publication profiles reveal the strengths and weaknesses of each country in terms of output. Whereas Japan has a rather balanced profile - which is quite typical for welldeveloped countries - and is thus active in all of the thirteen research areas, the other AsiaPacific countries tend to specialize in certain fields: Taiwan is strong in information and computer science and in engineering; Singapore in nanotechnology and information and computer science. Australia and New Zealand both focus on agricultural and geosciences. Together with their common cultural background, this might explain the strong co-publication ties between both nations. Among the Asia-Pacific countries, Australia is New Zealand's first collaboration partner, and New Zealand is Australia's second most important co-publication partner (see table 2 and figures 6 and 7).

A large number of articles only describe the basis of visibility not the actual perception, which can be measured by the number of citations. As has been shown in previous studies (Guan \& Ma, 2007; Moed, 2002), the present analysis confirms that Chinese citation rates lie well below expectations. A good example is China's publication and citation rate in materials 
science in 2007: with 14,389 articles and reviews, China published $27 \%$ of the worldwide output in this field as covered by the WoS databases (see figure 3a), while its citation rate lies about $23 \%$ below the world average (see figure $4 a$ ). Due to differing citation behavior, specific citation rates have been derived for research and review articles from each of the 13 disciplines. In 2007, the average citation rates range from 1.6 for mathematical papers to 15.5 for articles from the subject category of multidisciplinary sciences (table 1 ).

Table 1 Average global Citation Rates per Discipline for Articles and Reviews from 2007.

Figure 4a Field-normalized Citation Rates for Research and Review Articles published in 2007 by Australia, China, Japan, South Korea and Taiwan (World Average $=100 \%$ ).

Figures $4 \mathrm{a}$ and $4 \mathrm{~b}$ show the extent to which the countries' field-normalized citation rates lie above or below the world average (100\%). Since the study was conducted on behalf of a German government organization, the countries' citation rates in the study were compared to that of the benchmark Germany in individual disciplines (Haustein, Mittermaier \& Tunger, 2008). While in the present analysis, the average global citation rates are based on articles and reviews from the year 2007 only, the study for BMBF included citation data on all types of publications from 1998 to 2007. With mathematics and nanotechnology as the only disciplines below the world average, Australia performed as the best Asia-Pacific country in terms of visibility. Singapore followed with nine out of thirteen field-specific citation rates above average. Indonesia was the least visible country among the Asia-Pacific countries: it only met the world standard in medicine. In multidisciplinary journals, South Korean articles and reviews were cited twice as often as the average, but the country trailed behind in all of the other disciplines. In terms of visibility, Singapore was by far the most successful country in the Asia-Pacific region: in agricultural science, biology and biotechnology, chemistry, energy, engineering, materials science, mathematics, medicine and multidisciplinary journals, it had higher citation rates than any other country in the research area. It was only beaten in physics and in information and computer science by Australia, in the geosciences by Vietnam, and in nanotechnology by New Zealand. Singapore's high citation rates might be explained by its good knowledge infrastructure, for which the foundations were laid at the beginning of the 90s (Evers, Gerke \& Schweißhelm, 2004).

Figure 4b Field-normalized Citation Rates for Research and Review Articles published in 2007 by Indonesia, Malaysia, New Zealand, Singapore, Thailand and Vietnam (World Average = 100\%). 


\section{International collaboration}

In addition to focusing on scientific output on a national level, studies on research output also analyze collaboration between countries. The motives and reasons for scientists to collaborate can be subdivided into direct and indirect benefits. Among the direct advantages of working with scientists from other countries is the access to complementary knowledge or skills, unique sites and facilities (Birnholtz, 2007). One of the major reasons behind collaboration is to share costs and possible risks (Kim, 2005). International collaboration becomes inevitable when transnational or global problems need to be solved or when standards are to be established. Indirect benefits are also associated with international scientific collaboration. For example, science can function as an initial facilitator for future economic or political bonds (Georghiou, 1997). International collaboration is influenced by cognitive, social and cultural factors as geographic proximity, common language and by historical developments or the national education system (Inonu, 2003; Kim, 2005; Luukkonen, Persson \& Sivertsen, 1992; Wagner, Brahmakulam, Jackson, Wong \& Yoda, 2001). Political and economic changes influence science as well. Kim (2005) has shown that the economic change in South Korea had an impact on international collaboration. Price (1963) emphasized the importance of economic instead of intellectual dependency for collaborating in science.

The nature of scientific collaboration can either be formal or informal. Both "may lead to joint production of outputs" (Georghiou, 1997). Working together scientifically on an informal level includes communicating directly via telephone or e-mail or exchanging ideas, materials, and research results in face-to-face meetings. Informal cooperation is often characterized by the absence of a contract between the participants. Since informal collaboration is hard to measure, most science studies concentrate on the formal aspect of international collaboration. This can occur in the form of funded programs, conferences, patents, formal collaboration agreements or publications authored by researchers from different countries (Georghiou, 1997; Gupta, Munshi \& Mishra, 2004). As journals function as the main publication channel for research results in science, our analysis focuses on international collaboration in journal articles. An article is usually referred to as internationally co-authored, if the addresses of the authors' affiliations include more than one country (Luukkonen, Persson \& Sivertsen, 1992; Moed, 2002). Table 2 shows the square matrix of the absolute number of co-publications between the Asia-Pacific countries ${ }^{2}$ in 1998 and 2007.

Table 2 Number of Co-publications between the eleven Asia-Pacific Countries for 1998 and 2007. The Diagonal indicates the total Number of Publications for each Country for the particular Year.

Since a jointly published article does not indicate the direction or choice of cooperation in terms of who took the initiative, the matrix is symmetrical (Luukkonen, Persson \& Sivertsen, 1992). The diagonal indicates the total output of the respective country for the particular year 
and not the number of co-publications within a country. In table 2, the general increase in total publications from 1998 to 2007 can be observed. The number of co-publications within the analyzed area has risen as well. Over the past two decades, a general increase in scientific co-publication has been ascertained in many places (Georghiou, 1997; Luukkonen, Persson \& Sivertsen, 1992; Wagner, Brahmakulam, Jackson, Wong \& Yoda, 2001; Wagner, Yezril \& Hassell, 2001).

International scientific collaboration - where scientists work with their counterparts in other countries towards a common research goal - is growing as a percentage of all scientific activity. (Wagner, Brahmakulam, Jackson, Wong \& Yoda, 2001)

Figure 5 Percentage of Articles and Reviews that a Country published together with at least one international Partner from 1998 to 2007.

Figure 5 shows this percentage for each country in Asia-Pacific, where international scientific collaboration is defined as the share of articles and reviews published together with at least one author from another country worldwide. In general, the Asian-Pacific countries with a very high yearly output - i.e. China, Japan, South Korea and Taiwan - co-publish only a small percentage (up to 28\%) on an international basis, whereas countries with a smaller output generate almost half up to $90 \%$ of their scientific papers in collaboration with other nations. Indonesia and Vietnam, the two countries analyzed with the least scientific output, have by far the highest percentage. The coherence between country size in terms of output and the share of internationally co-authored papers has been ascertained by others in the past (Luukkonen, Persson \& Sivertsen, 1992).

At the national level, the share of international collaboration in large countries is necessarily lower than that of medium-sized or even small countries. (Schubert \& Braun, 1990)

Wagner, Brahmakulam, Jackson, Wong and Yoda (2001) differentiate between scientifically advanced, proficient, developing and lagging countries and assume a positive coherence of R\&D investments and economic growth. Since a co-publication does not reveal which partner was the driving force behind the collaboration, we do not know if a high share of international collaboration indicates that the respective country chose or was chosen to cooperate. Therefore, a high degree of international collaboration could either stand for dependence or expertise, and a low level may be evidence of independence or isolation. Glänzel and Schubert (2007) have outlined that international collaboration in general has positive aspects but they also pointed out the problems linked to it. It may be assumed that countries like Thailand and Vietnam benefit from collaborating with other research nations (Luukkonen, Persson \& Sivertsen, 1992). 
With a fairly high publication output and over $40 \%$ of its total publications in 2007 being internationally co-authored, Australia is an exception to the rule. It is also one of the countries with the strongest increase in international collaboration over the ten years analyzed. Only New Zealand (from 38\% to 52\%) and Singapore (from 32\% to 48\%) show higher growth rates between 1998 and 2007. Thailand, China and Vietnam are the only Asia-Pacific countries where the share of internationally co-authored articles and reviews decreased over the ten years analyzed. The mean value of internationally co-authored papers for all AsiaPacific countries was 41\% in 1998 and 46\% in 2007, allowing a general tendency towards formal international collaboration to be assumed for the countries analyzed.

Since a general increase in international co-publication has been ascertained on a global scale, we shall now examine the extent to which scientific collaboration between the countries in the Asia-Pacific region has developed according to the worldwide trend and evaluate whether they experienced an above-average increase. The question is raised as to whether bibliometric measures indicated the existence or development of an Asia-Pacific research area. Figure 6 depicts the number of publications for each country in 1998 in contrast to their share of a country's scientific output published within the research area. The latter is defined as the number of articles a country has co-published with at least one other of the eleven countries analyzed. Thus, the percentage share indicates the level of cooperation within the Asia-Pacific network. The results for cooperation within the network are similar to the findings for the share of worldwide co-publications of the Asia-Pacific countries in figure 5: Countries with a low output generate a large share of their research results within the defined region. On the contrary, countries with a high scientific output, contribute a rather low share of articles to the region proportionally (Luukkonen, Persson \& Sivertsen, 1992).

Figure 6 Comparison of Publication Output and the Share of Articles published within the Asia-Pacific Region for each Country in 1998.

Figure 7 Comparison of Publication Output and the Share of Articles published within the Asia-Pacific Region for each Country in 2007.

Indonesia is the country with the highest share of research output jointly published with at least one of the other members of the region: almost a third of its publications were generated within Asia-Pacific in 1998. At this point, the differences between small and large countries must be considered: even though Indonesia co-publishes almost a third of its output within the network, it contributes only about 130 papers to the regional output, whereas Japan publishes around 2,360 papers together with at least one other Asia-Pacific country. Indonesia's most important partners in Asia-Pacific are Japan, Australia and Thailand. The USA remains the most important ally on a global scale. Germany is forth in 
terms of Indonesian research collaboration. With 399 publications, Indonesia published the second lowest number of journal articles in 1998 within the analyzed region, behind Vietnam, which published 253. Japan, on the other hand, was well ahead of all the other members of the Asia-Pacific region with 78,504 publications, but it only contributed $3 \%$ of its annual output to the research area. The most important partners for Japanese scientists come from the USA, Germany and the UK. China features as the first cooperation partner from the analyzed network in forth place. South Korea and Australia follow in seventh and eighth place. Regardless of its low relative share, Japan still produces the most articles in 1998. Half of the Asian-Pacific output is authored by Japanese researchers. Australia and Chinese researchers follow with $17 \%$ and $13 \%$, respectively. Nine years later, the situation has changed (see figure 9): due to its exponential growth, China has become the most important country in the network in terms of the number of publication. With 34\%, it accounts for a third of all publications in the area. Japan, New Zealand and Australia lost ground to the other contributors. Comparing figures 6 and 7, an increase in annual publications can be observed as can growth in the share of collaboration within the network of the eleven countries. All of the countries analyzed do not only publish more in absolute numbers, but they also show an above-average increase in the number of articles they produce together with at least one other Asia-Pacific country. The two variables of publication number and percentage collaboration share still correlate highly negatively, and thus confirm general findings on size in terms of output and collaboration in terms of internationally co-authored papers (Luukkonen, Persson \& Sivertsen, 1992). Since the overall share of output published within the research area has grown, the network integration has increased. Indonesia remained the smallest country in terms of output and published almost half of its scientific results in cooperation with other countries in the Asia-Pacific region in 2007.

Table 3 Internationally collaborating Countries for the largest and smallest of the Asia-Pacific Countries in 1998 (Japan and Indonesia) and 2007 (China and Indonesia). Partners within the AsiaPacific Region are highlighted.

As can be seen in table 3, the number of Asia-Pacific countries in the top 10 international collaborators has increased for Indonesia as well, and Japan has replaced the USA as the most important co-publishing partner. The extremely high share of co-published articles by countries in the Asia-Pacific region with a low annual output suggests a high dependency on the larger and more developed countries.

"[T]o avoid isolation, scientists from smaller countries have to look for partners from scientifically more central ones. The increasing specialization in science makes research areas more narrowly focused and scientists from scientifically peripheral countries are likely to find only a few, if any, colleagues in their own country. Another reason for their high rate of international collaboration might be their greater need for cost sharing." (Luukkonen, Persson \& Sivertsen, 1992) 
Since the cooperation values also for increase Japan and Australia, however, we can speak of increasing collaboration within the network and not only a center-periphery relationship between the large and small countries in the Asia-Pacific region (Luukkonen, Tijssen, Persson \& Sivertsen, 1993).

A strengthening of the cooperation bonds between the countries can be observed in the network diagrams in figure 8 and 9 . The lines indicate the number of co-authored journal articles in 1998 and 2007 within the eleven countries analyzed, which are represented by the vertices. The thicker the lines, the more the two respective countries collaborated. The number of joint publications has been normalized with respect to the total output of the two countries by applying Salton's measure of international collaboration strength (S) (Glänzel \& Schubert, 2007; Salton \& McGill, 1986). It measures the strength of the bond between two countries $x$ and $y$ by dividing their co-authored papers $C_{x y}$ by the square root of the product of the total output of the two countries $\mathrm{C}_{\mathrm{x}}$ and $\mathrm{C}_{\mathrm{y}}$ :

$$
S_{x y}=\frac{C_{x y}}{\sqrt{C_{x} \cdot C_{y}}}
$$

Thus, Salton's measure considers differences in the sizes of output of the two collaborating countries. Since the co-publications are normalized with respect to the countries' output, the strengthening of the network cannot be explained by the overall increase in scientific output. The members of the research area have rather increased their collaboration above expectations. An analysis of the co-publication network of ten selected ${ }^{3}$ countries $^{4}$ (further referred to as sample countries) did not show such an intensification of cooperation (compare figures 10 and 11). A slight increase in international collaboration for these countries can indeed be seen, but this is not comparable to the strengthening of the AsiaPacific network. In fact, strong bonds in the network of sample countries can be observed, especially between countries in the same geographic or cultural area, e.g. France and Germany, Russia and Ukraine, Japan and South Korea, as well as Argentina and Brazil, respectively (see figures 10 and 11). This indicates the influence of cultural backgrounds on scientific cooperation as mentioned above. Only the growth in the relative co-operation of Russia with France and Germany, respectively, cannot be explained by such reasons (see figure 11). In this case, the decrease in the absolute number of Russian publications from 1998 to 2007 could play a decisive role.

Figure 8 Co-publications between the Asia-Pacific Countries in 1998 normalized with Salton's International Collaboration Strength. 
Figure 9 Co-publications between Asia-Pacific Countries in 2007 normalized with Salton's International Collaboration Strength.

Figure 10 Co-publications between ten Sample Countries ${ }^{5}$ in 1998 normalized with Salton's International Collaboration Strength.

Figure 11 Co-publications between ten Sample Countries ${ }^{5}$ in 2007 normalized with Salton's International Collaboration Strength.

\section{Concluding Remarks}

As Glänzel and Schubert have stated, international collaboration "is accepted as a basically positive phenomenon" (Glänzel \& Schubert, 2007). This paper has shown this and has explained why researchers collaborate with colleagues from other nations. By analyzing author affiliation addresses in scientific journal articles, the most common method of international scientific cooperation was examined for eleven countries from the Asia-Pacific region. Findings on the general increase in publication output and international cooperation in science were validated. Discipline-specific publication profiles revealed the strengths and weaknesses of countries in different scientific fields. Normalized citation rates have shown that a high output does not necessarily lead to great visibility, which has especially proven true for China.

With different approaches and indicators, the publication behavior of and among the eleven Asia-Pacific countries was analyzed. The results allow the conclusion that international cooperation between the countries in the Asia-Pacific region has intensified between 1998 and 2007, and that an Asia-Pacific research area does exist from a bibliometric perspective. Comparing the co-publication network of the Asia-Pacific countries to a network for a set of sample countries, it was confirmed that inner-Asian scientific collaboration has developed more than the global average. To be able to speak about the emergence of an Asia-Pacific research area in general, an evaluation of the scientific, political, socioeconomic, historic and cultural frameworks in and relations between the Asia-Pacific countries is required. 


\section{Acknowledgements}

The authors would like to thank the International Bureau of BMBF for commissioning the underlying study. We would also like to thank the Bibliometrics department in the Central Library at Forschungszentrum Jülich for comprehensive technical support and Hazel Burlet at the Language Services for proofreading this paper.

\footnotetext{
${ }^{1}$ The analyzed countries will be further referred to as Asia-Pacific countries.

${ }^{2}$ AUS=Australia, $\mathrm{CHN}=$ China, IDN=Indonesia, JPN=Japan, MYS=Malaysia, NZL=New Zealand, $\mathrm{SGP}=$ Singapore, KOR=South Korea, TWN=Taiwan, THA=Thailand, VNM=Vietnam.

${ }^{3}$ The countries were chosen to represent a mixed sample set in terms of output and location.

${ }^{4}$ Argentina, Brazil, France, Germany, Japan, Mexico, Russia, South Africa, South Korea and Ukraine.

${ }^{5} \mathrm{ARG}=$ Argentina, $B R A=$ Brazil, FRA=France, GER=Germany, JAP=Japan, KOR=South Korea, MEX=Mexico, RSA=South Africa, RUS=Russia, UKR=Ukraine.
}

\section{References}

Birnholtz, J.P. (2007). When do researchers collaborate? Toward a model of collaboration propensity. Journal of the American Society for Information Science and Technology, 58 (14), 2226-2239.

Evers, H.-D., Gerke, S., \& Schweißhelm, R. (2004). Malaysia, Singapur, Indonesien: Wege zur Wissensgesellschaft. South East Asian Studies 20. Bonn: University of Bonn, Department of Southeast Asian Studies. Retrieved March 8, 2010, from http://edoc.huberlin.de/evifa/documents/books/reV5yMleTTSYI/PDF/239Wf25iK8dcl.pdf

Frame, J.D., Narin, F., \& Carpenter, M.P. (1977). Distribution of world science. Social Studies of Science, 7 (4), 501-516.

Georghiou, L. (1997, Jun 16-17). In Global cooperation in research (Vol. 27, pp. 611-626). Paper presented at the Conference on the Past and Future of EU Research Funding-Framework Programmes under Consideration, Helsinki, Finland.

Glanzel, W., Debackere, K., \& Meyer, M. (2008). 'Triad' or 'tetrad'? On global changes in a dynamic world. Scientometrics, 74 (1), 71-88.

Glänzel, W., \& Schubert, A. (2007). Analysing scientific networks through co-authorship. In Moed, H.F., Glänzel, W. \& U. Schmoch (Eds.), Handbook of Quantitative Science and Technology Research. The Use of Publication and Patent Statistics in Studies of S\&T Systems (pp. 257276). Dordrecht / Boston / London: Kluwer Academic Publishers.

Gómez, I., \& Méndez, A. (1992). Are peripheral countries profiting from scientific cooperation networks? In P. Weingart, R. Sehringer \& M. Winterhager (Eds.), Representations of Science and Technology: Proceedings of the International Conference on Science and Technology Indicators (pp. 112-123). Leiden: DSWO Press.

Guan, J.C., \& Ma, N. (2007). A bibliometric study of China's semiconductor literature compared with other major asian countries. Scientometrics, 70 (1), 107-124.

Gupta, B.M., Munshi, M., \& Mishra, P.K. (2004). Regional collaboration in S\&T among South Asian countries. Annals of Library and Information Studies, 51 (4), 121-132.

Haustein, S., Mittermaier, B., \& Tunger, D. (2008). Bibliometric Analysis Asia-Pacific Research Area. commissioned by the International Bureau of the BMBF at DLR. Jülich: Forschungszentrum Jülich. Retrieved March 8, 2010, from http://www.kooperationinternational.de/index.php?eID=tx_nawsecuredl\&u=0\&file=fileadmin/redaktion/doc/Bibliometri e_Asien_englisch_neu.pdf $\& t=1268142711 \&$ hash=311621d7ca9cd94af219c315eb9ba97e

Heinrichs, G., Baelz, G., Haustein, S., \& Tunger, D. (to be published). Entwicklung der Forschungskooperationen Deutschlands mit dem asiatisch-pazifischen Raum - Chancen und Herausforderungen.

Inonu, E. (2003). The influence of cultural factors on scientific production. Scientometrics, 56 (1), 137146.

Kim, M.J. (2005). Korean science and international collaboration, 1995-2000. Scientometrics, 63 (2), 321-339. 
King, D.A. (2004). The scientific impact of nations. Nature, 430 (6997), 311-316.

Luukkonen, T., Persson, O., \& Sivertsen, G. (1992). Networks of international scientific collaboration, In P. Weingart, R. Sehringer \& M. Winterhager (Eds.), Representations of Science and Technology: Proceedings of the International Conference on Science and Technology Indicators (pp. 95-111). Leiden: DSWO Press.

Luukkonen, T., Tijssen, R.J.W., Persson, O., \& Sivertsen, G. (1993). The measurement of international scientific collaboration. Scientometrics, 28 (1), 15-36.

Martinez, C., \& Moore, T. (2008). China goes from strength to strength. Inspec Matters (October 2008).

Moed, H.F. (2002). Measuring China's research performance using the Science Citation Index. Scientometrics, 53 (3), 281-296.

Okubo, Y., Dore, J.C., Ojasoo, T., \& Miquel, J.F. (1998). A multivariate analysis of publication trends in the 1980s with special reference to south-east Asia. Scientometrics, 41 (3), 273-289.

Price, D.J.D.S. (1963). Little Science, Big Science. New York / London: Columbia University Press.

Salton, G., \& McGill, M.J. (1986). Introduction to Modern Information Retrieval. New York: McGraw-Hill Inc.

Schubert, A., \& Braun, T. (1990). International collaboration in the sciences, 1981-1985. Scientometrics, 19 (1-2), 3-10.

Tunger, D. (2009). Bibliometrische Verfahren und Methoden als Beitrag zur Trendbeobachtung und erkennung in den Naturwissenschaften. Jülich: Forschungszentrum Jülich $\mathrm{GmbH}$, Zentralbibliothek, Verlag. Retrieved March 8, 2010, from http://epub.uniregensburg.de/12294/1/Bibliothek_19_uni.pdf

Wagner, C.S., Brahmakulam, I., Jackson, B., Wong, A., \& Yoda, T. (2001). Science and Technology Collaboration: Building Capacity in Developing Countries? Santa Monica: RAND. Retrieved March 8, 2010 from http://www.rand.org/pubs/monograph_reports/2005/MR1357.0.pdf

Wagner, C.S., Yezril, A., \& Hassell, S. (2001). International Cooperation in Research and Development. An Update to an Inventory to U.S. Government Spending: RAND. Retrieved March 8, 2010, from http://www.rand.org/pubs/monograph_reports/2007/MR1248.pdf 
Fig 1a

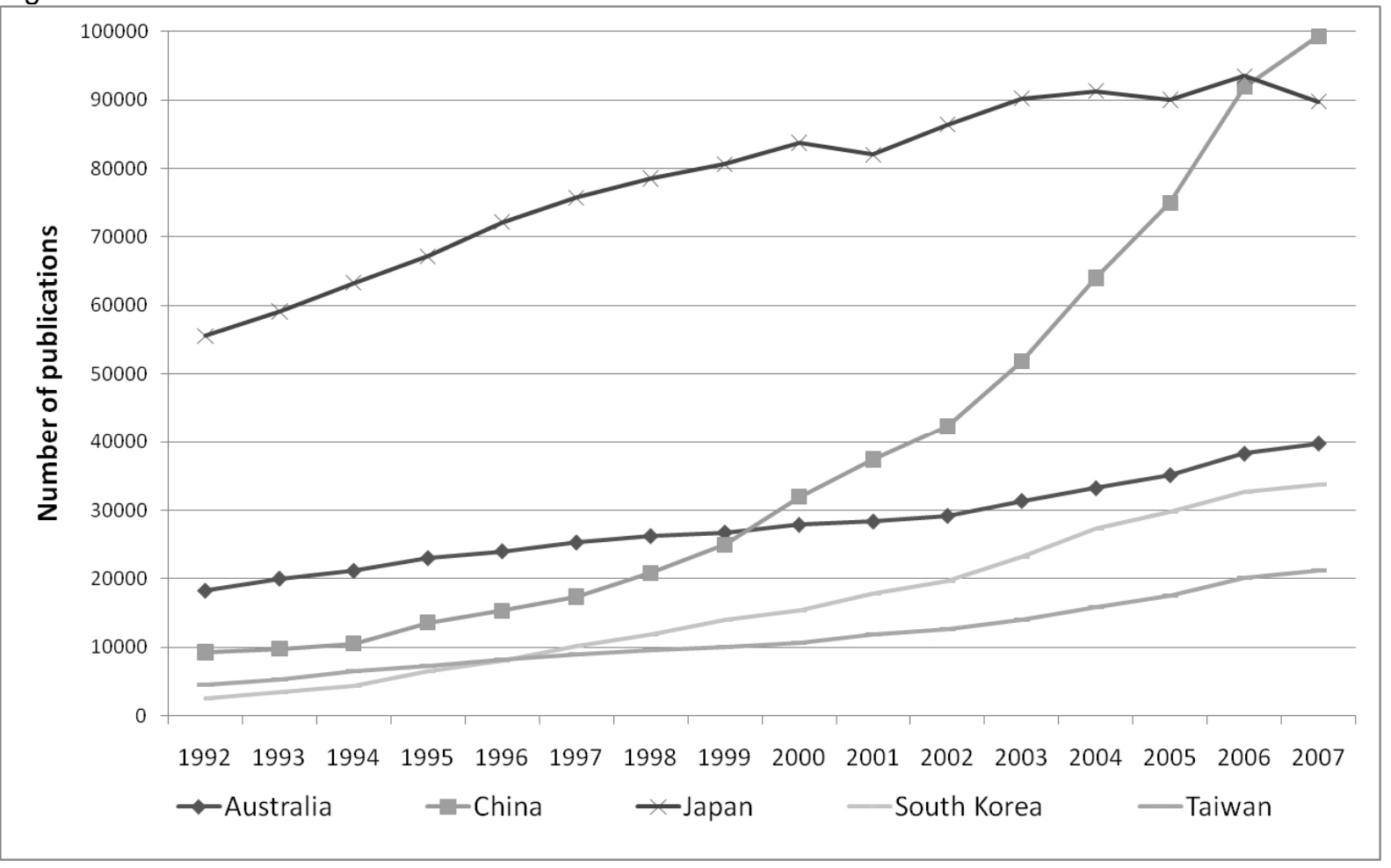

Fig $1 b$

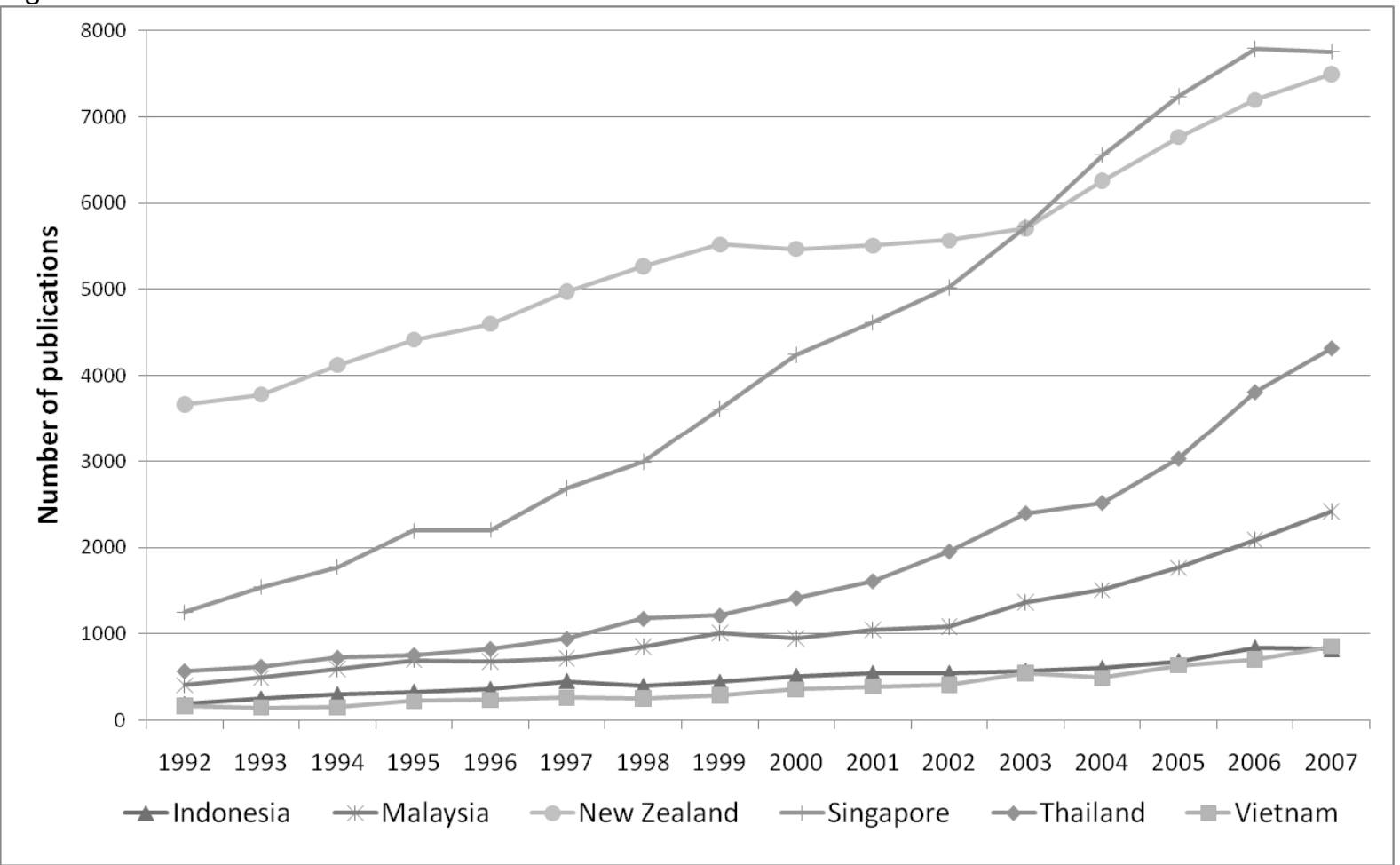


Fig 2

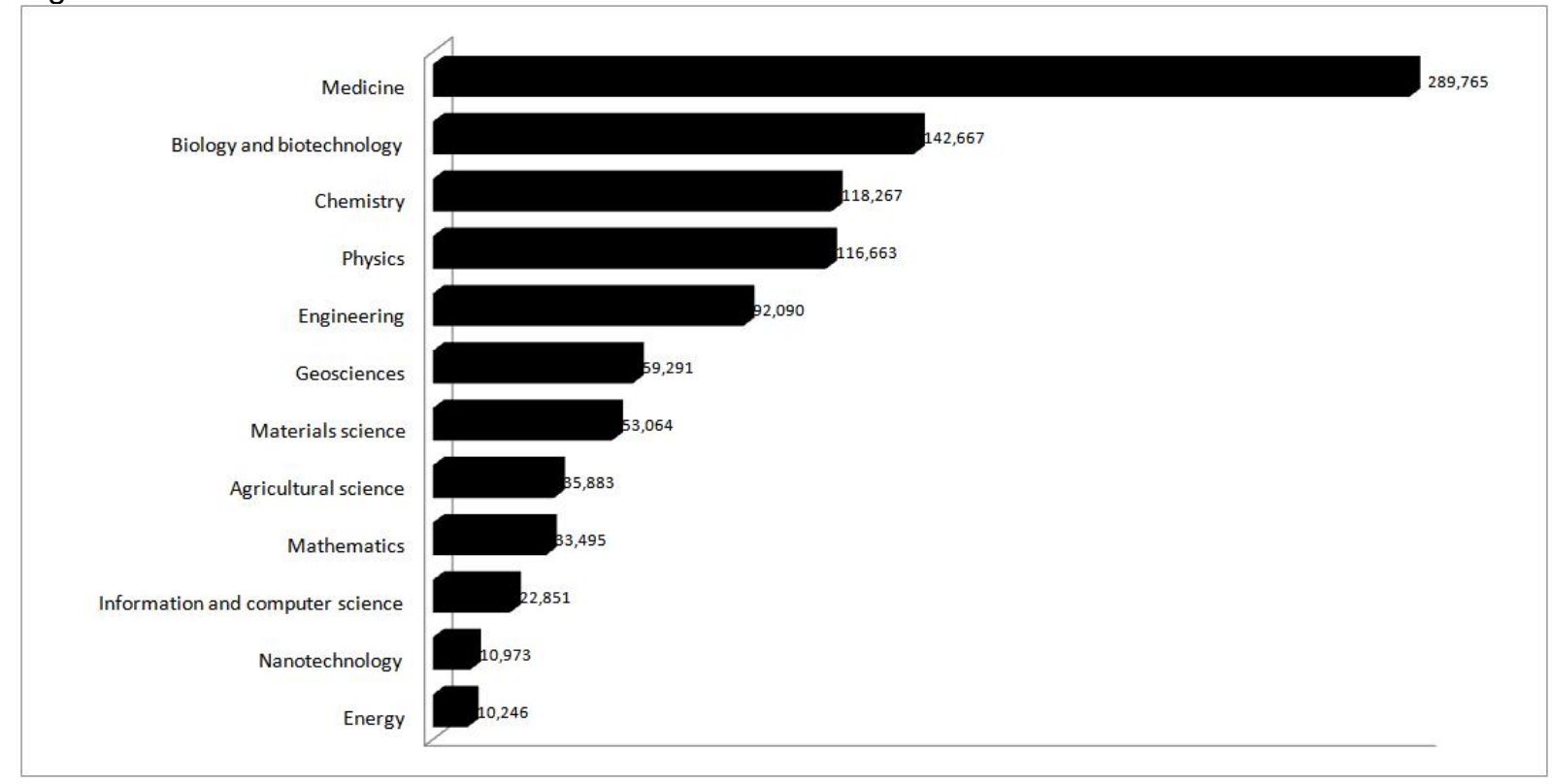

Fig $3 a$

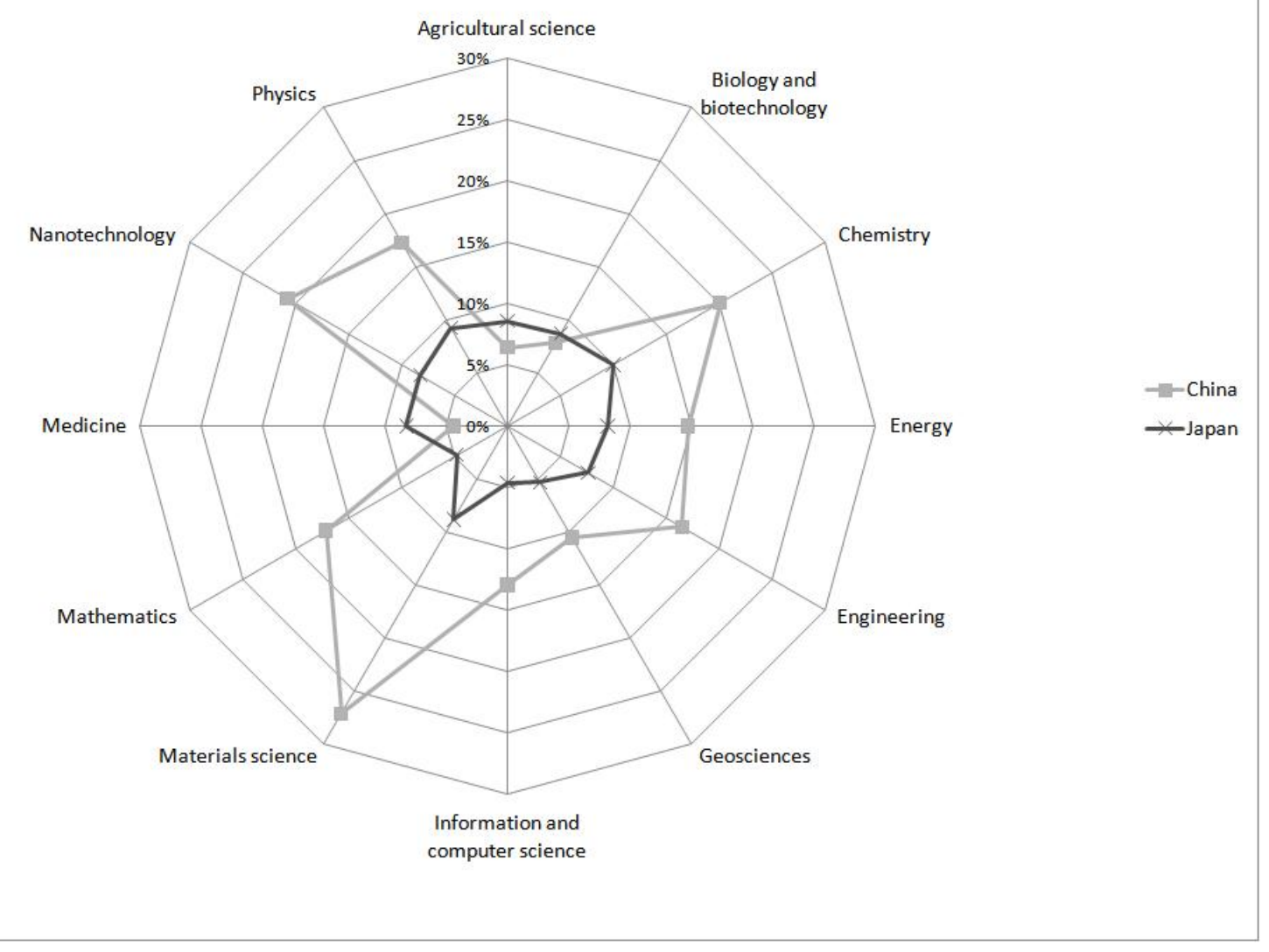


Fig $3 b$

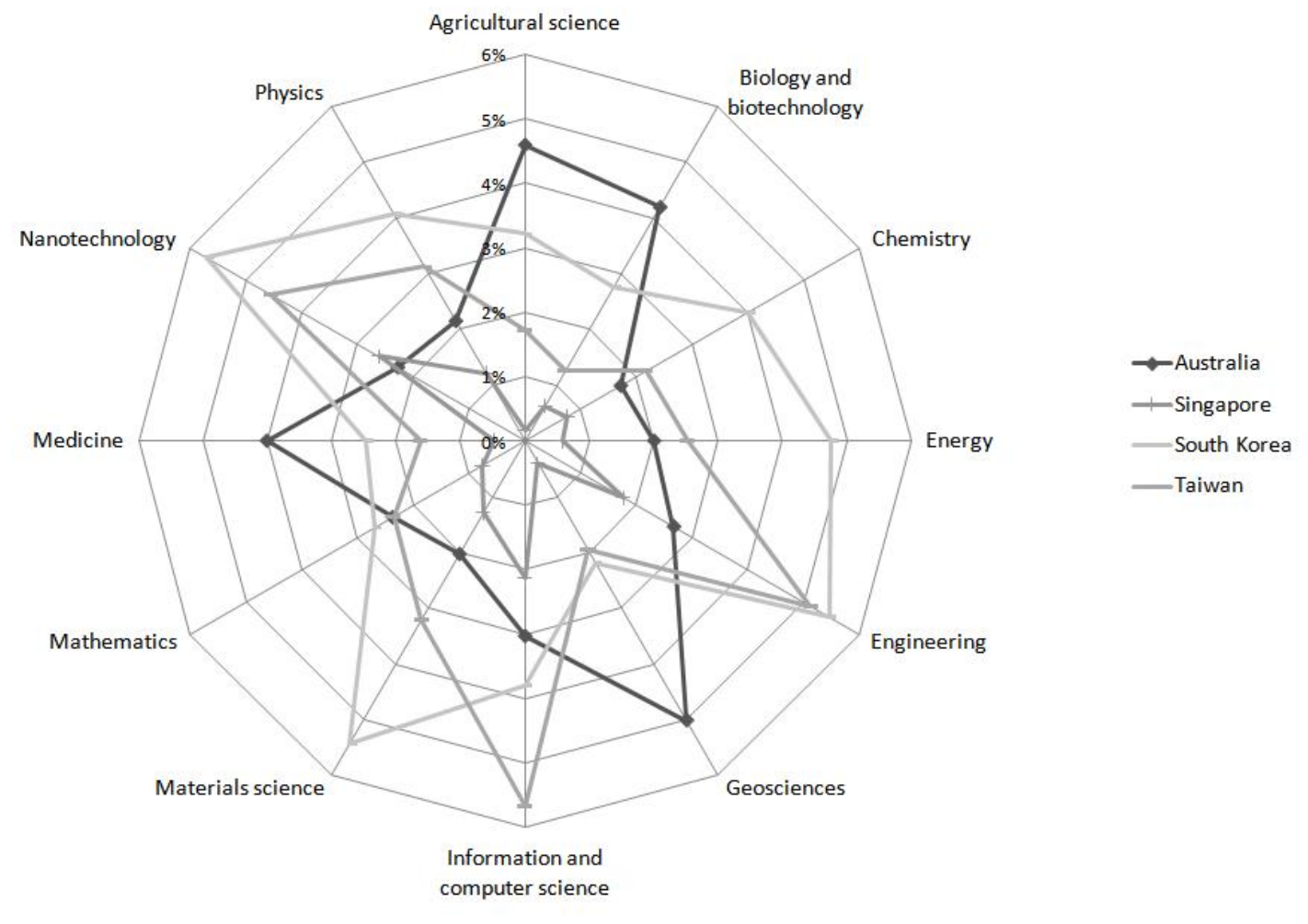

Fig $3 c$

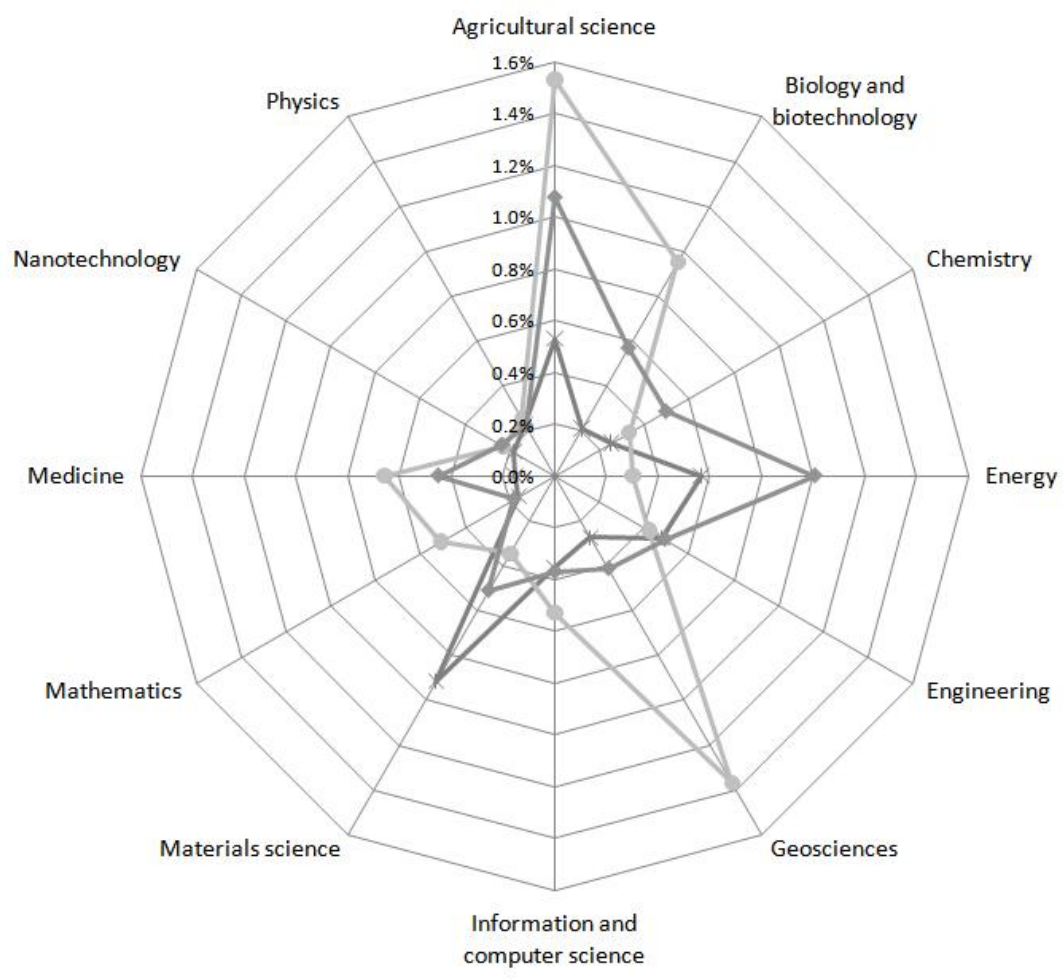


Fig 3d

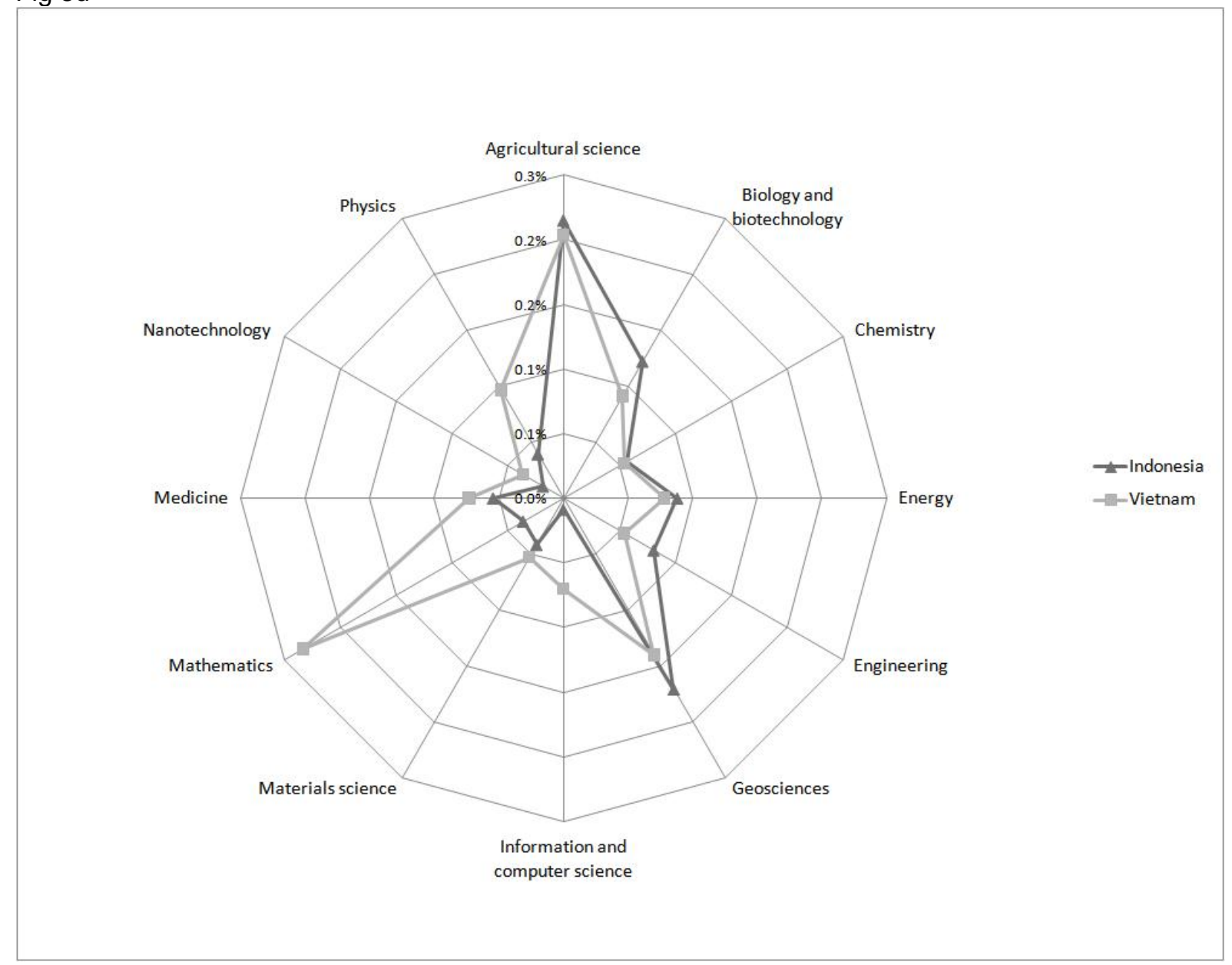

Fig 4a

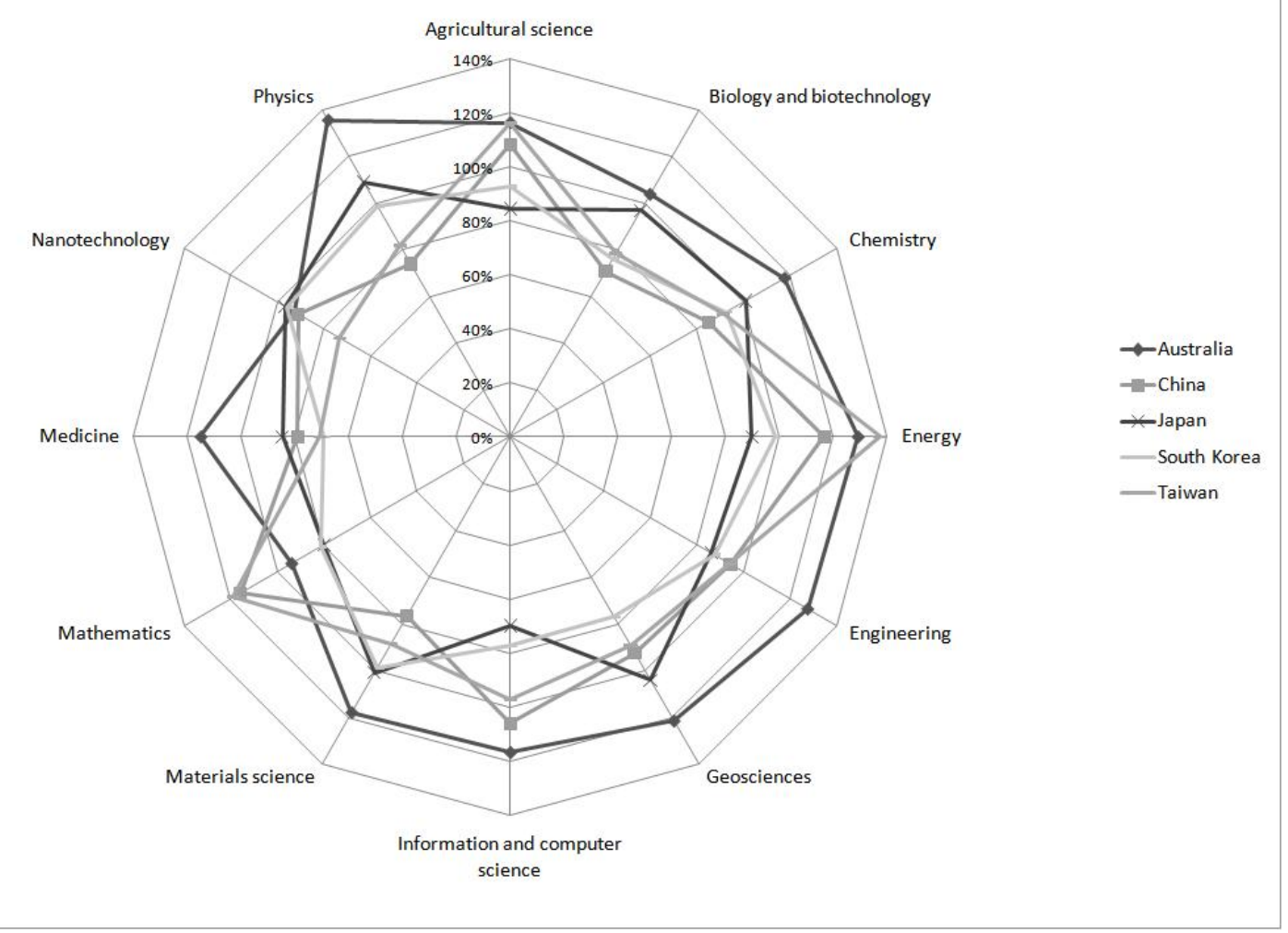


Fig 4b

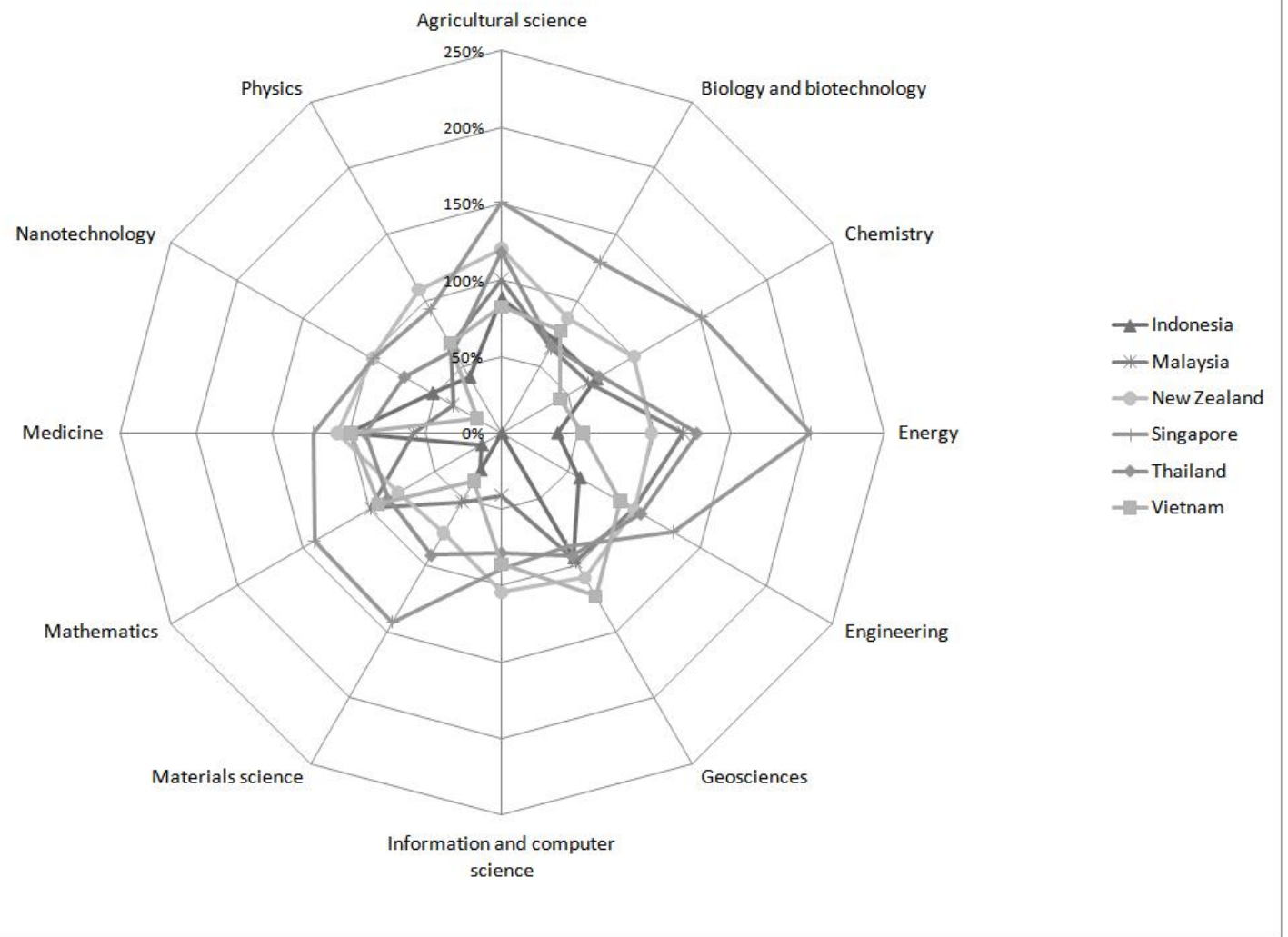

Fig 5

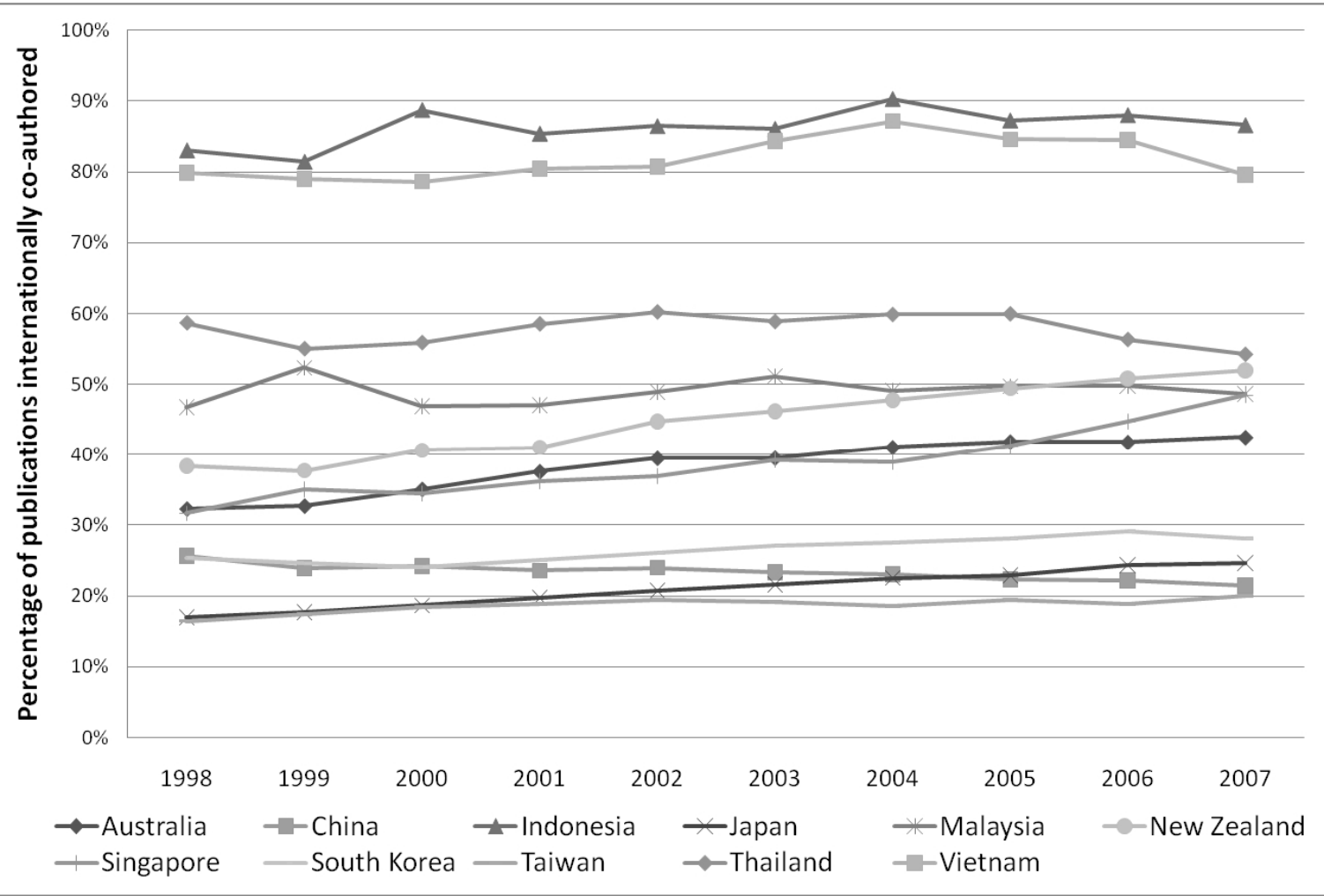


Fig 6

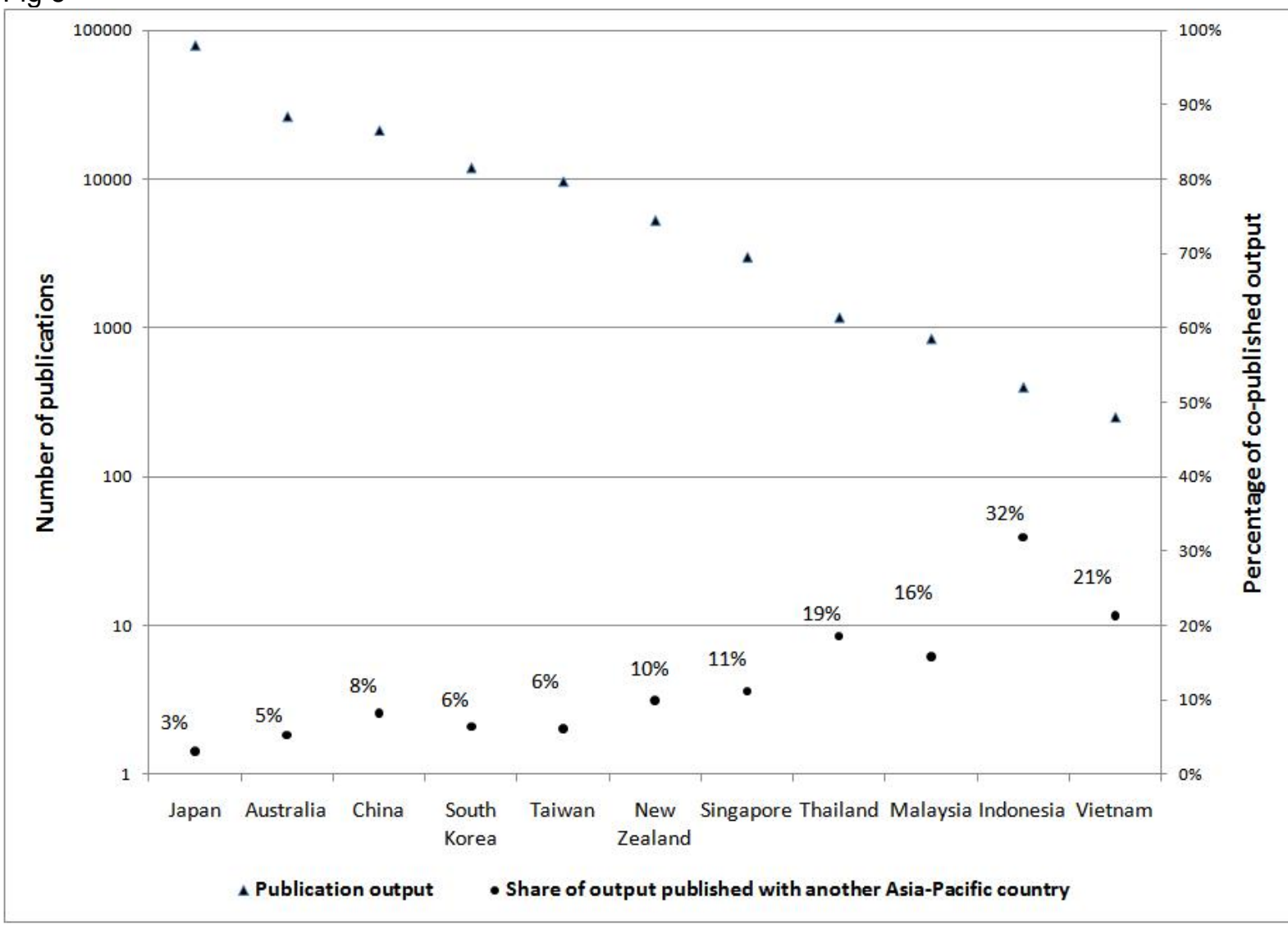

Fig 7

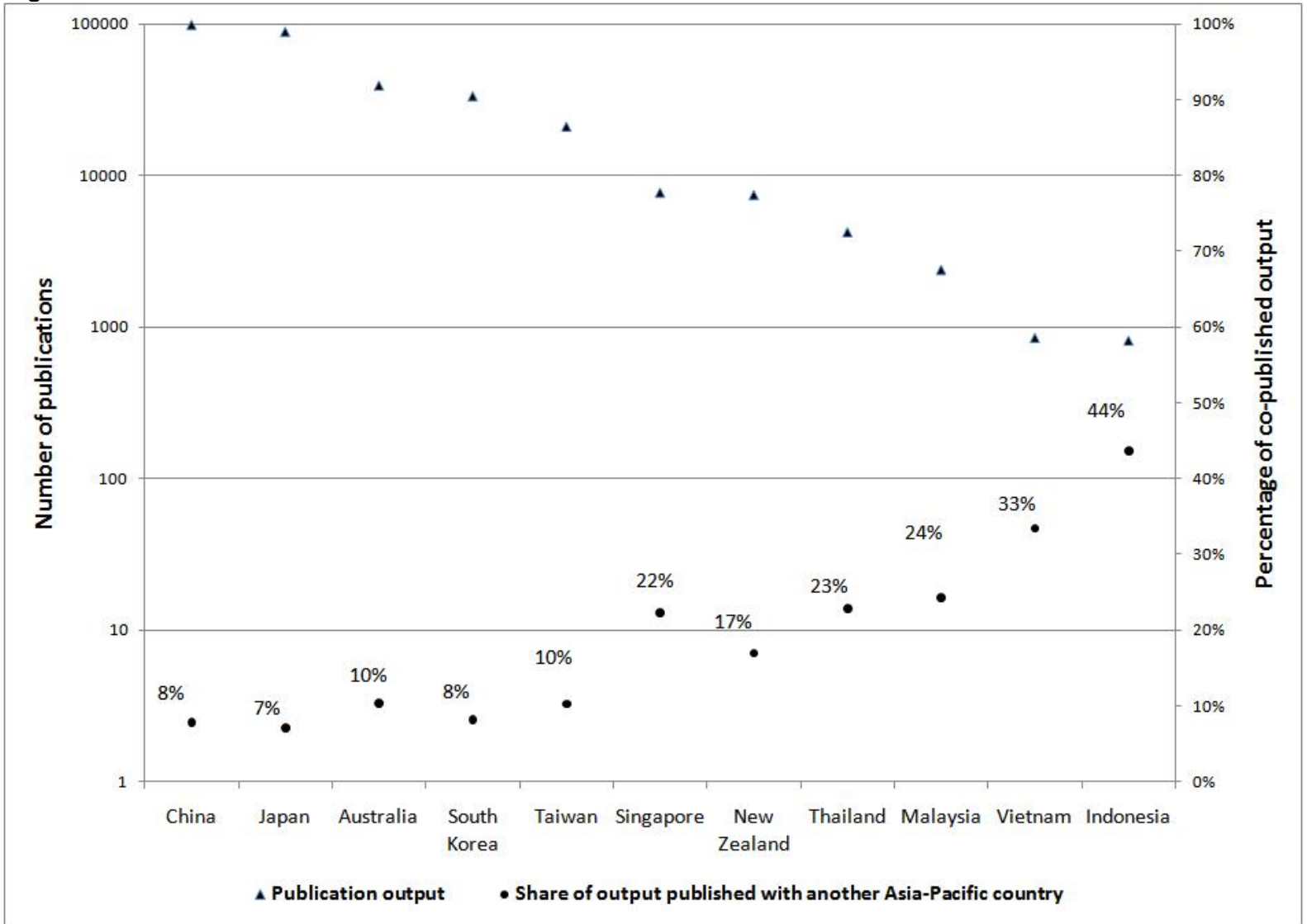


Fig 8

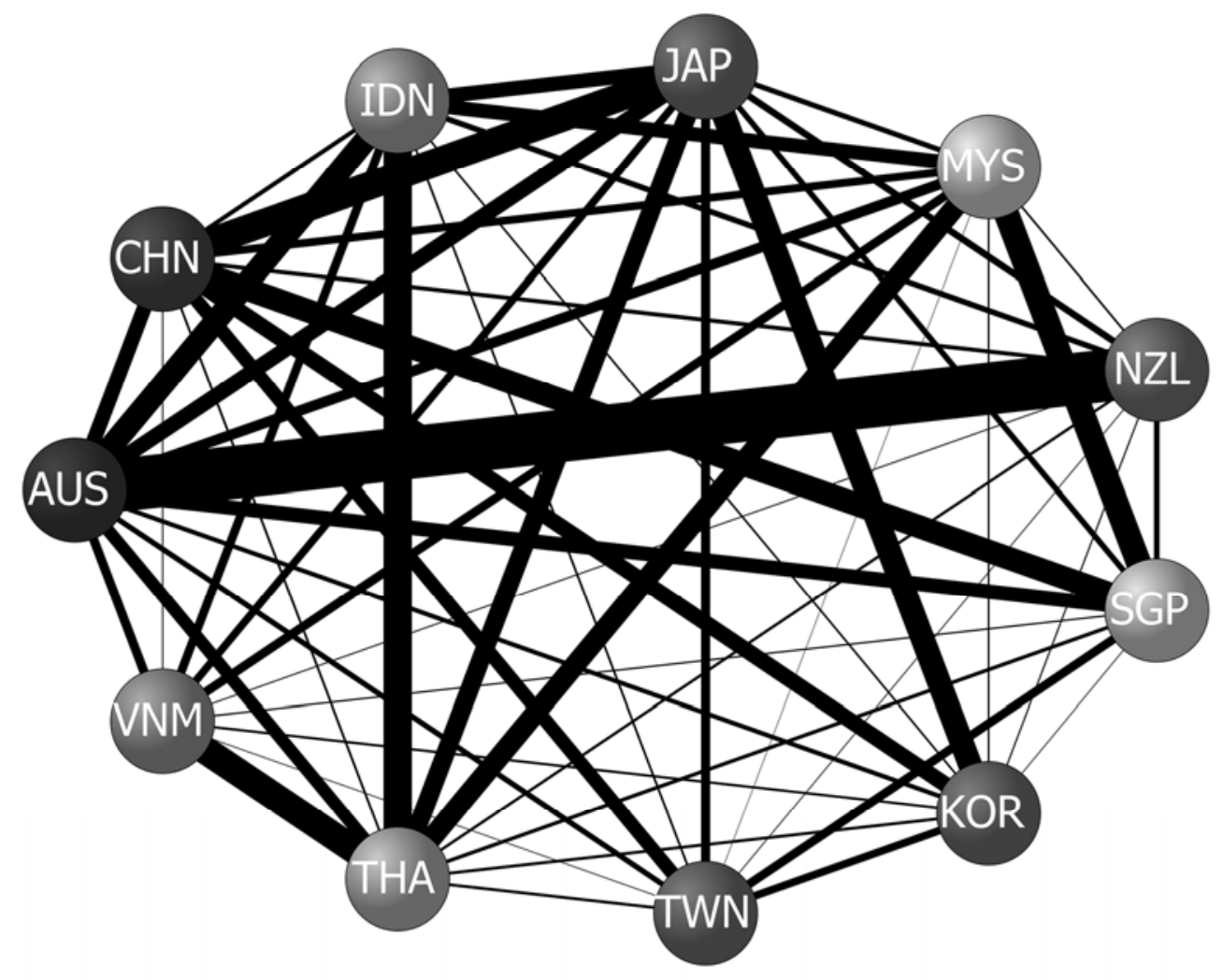

Fig 9

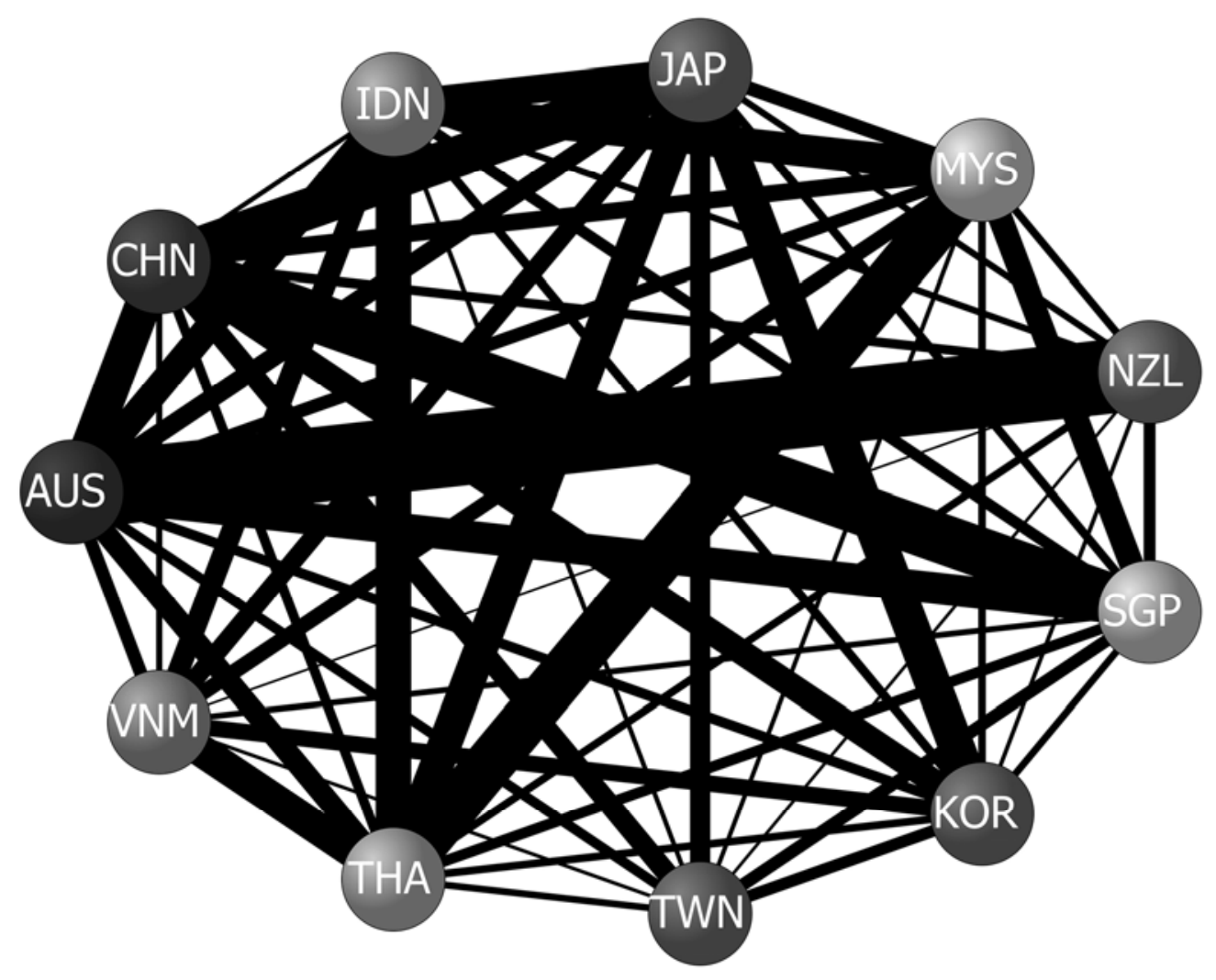





\begin{tabular}{|l|r|}
\hline & $\begin{array}{l}\text { Median of } \\
\text { annual increase } \\
\text { in publications }\end{array}$ \\
\hline China & $20 \%$ \\
\hline Thailand & $17 \%$ \\
\hline Malaysia & $15 \%$ \\
\hline Vietnam & $15 \%$ \\
\hline South Korea & $11 \%$ \\
\hline Taiwan & $11 \%$ \\
\hline Singapore & $10 \%$ \\
\hline Indonesia & $6 \%$ \\
\hline Australia & $4 \%$ \\
\hline New Zealand & $4 \%$ \\
\hline Germany & $3 \%$ \\
\hline Japan & $3 \%$ \\
\hline
\end{tabular}




\begin{tabular}{|lr|}
\hline \multicolumn{2}{|c|}{$\begin{array}{c}\text { Discipline specific citation rates for } \\
\text { articles and reviews published in } \mathbf{2 0 0 7}\end{array}$} \\
\hline Discipline & Average citation rate \\
\hline Agricultural science & 2.4 \\
Biology and biotechnology & 5.2 \\
Chemistry & 4.8 \\
Energy & 3.1 \\
Engineering & 2.4 \\
Geosciences & 3.0 \\
Information and computer sciences & 2.3 \\
Materials science & 3.4 \\
Mathematics & 1.6 \\
Medicine & 4.9 \\
Nanotechnology & 6.7 \\
Physics & 4.3 \\
\hline
\end{tabular}


Tab 3

\begin{tabular}{lrrrrrrrrrrrr} 
1998 & AUS & \multicolumn{1}{c}{ CHN } & IDN & \multicolumn{1}{c}{ JPN } & \multicolumn{1}{c}{ MYS } & NZL & SGP & KOR & TWN & THA & VNM \\
AUS & 26233 & 251 & 54 & 506 & 36 & 447 & 93 & 58 & 63 & 51 & 17 \\
CHN & 251 & 20818 & 9 & 820 & 24 & 31 & 132 & 180 & 142 & 8 & 2 \\
IDN & 54 & 9 & 399 & 59 & 6 & 6 & 0 & 3 & 3 & 14 & 2 \\
JPN & 506 & 821 & 59 & 78504 & 31 & 100 & 64 & 529 & 179 & 129 & 25 \\
MYS & 36 & 24 & 6 & 31 & 849 & 3 & 29 & 4 & 1 & 15 & 3 \\
NZL & 447 & 31 & 6 & 100 & 3 & 5272 & 16 & 8 & 5 & 5 & 1 \\
SGP & 93 & 132 & 0 & 64 & 29 & 16 & 2991 & 4 & 34 & 5 & 1 \\
KOR & 58 & 180 & 3 & 529 & 4 & 8 & 4 & 11893 & 60 & 8 & 3 \\
TWN & 63 & 142 & 3 & 180 & 1 & 5 & 34 & 60 & 9617 & 7 & 1 \\
THA & 51 & 8 & 14 & 129 & 15 & 5 & 5 & 8 & 7 & 1179 & 11 \\
VNM & 17 & 2 & 2 & 25 & 3 & 1 & 1 & 3 & 1 & 11 & 253
\end{tabular}

2007 AUS CHN IDN JPN MYS NZL SGP KOR TWN THA VNM

$\begin{array}{llllllllllll}\text { AUS } & 39571 & 1630 & 115 & 823 & 94 & 930 & 403 & 270 & 211 & 204 & 56\end{array}$ $\begin{array}{llllllllllll}\text { CHN } & 1630 & 98957 & 31 & 2821 & 189 & 185 & 1003 & 1062 & 694 & 146 & 41\end{array}$

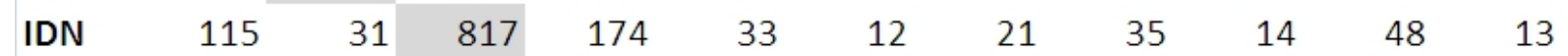

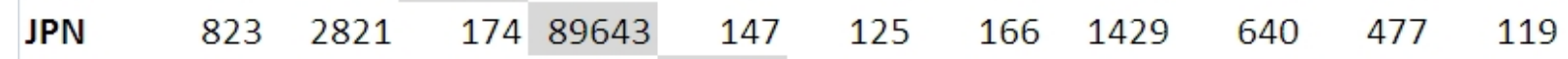

\begin{tabular}{lllll|lllllll} 
MYS & 94 & 189 & 33 & 147 & 2402 & 24 & 76 & 49 & 23 & 114 & 16
\end{tabular}

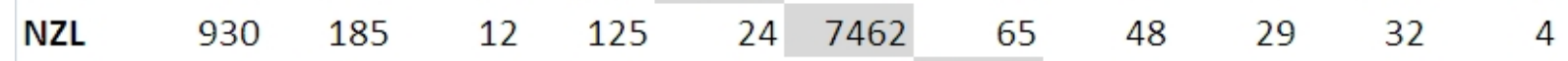

$\begin{array}{llllllllllll}\text { SGP } & 403 & 1003 & 21 & 166 & 76 & 65 & 7741 & 84 & 117 & 45 & 11\end{array}$

$\begin{array}{llllllllllll}\text { KOR } & 270 & 1062 & 35 & 1429 & 49 & 48 & 84 & 33701 & 232 & 67 & 64\end{array}$

$\begin{array}{llllllllllll}\text { TWN } & 211 & 694 & 14 & 640 & 23 & 29 & 117 & 232 & 21221 & 47 & 11\end{array}$

$\begin{array}{llllllllllll}\text { THA } & 204 & 146 & 48 & 477 & 114 & 32 & 45 & 67 & 47 & 4254 & 45\end{array}$

$\begin{array}{llllllllllll}\text { VNM } & 56 & 41 & 13 & 119 & 16 & 4 & 11 & 64 & 11 & 45 & 855\end{array}$ 
Tab 4

\begin{tabular}{|c|c|c|c|c|c|}
\hline \multicolumn{6}{|c|}{1998} \\
\hline \multicolumn{3}{|c|}{ Rank JAPAN (largest output) } & Rank & \multicolumn{2}{|c|}{ INDONESIA (smallest output) } \\
\hline & total output & 78504 & - & total output & 399 \\
\hline 1 & USA & 6071 & 1 & USA & 87 \\
\hline 2 & GERMANY & 1314 & 2 & JAPAN & 59 \\
\hline 3 & UK & 1212 & 3 & AUSTRALIA & 54 \\
\hline 4 & CHINA & 820 & 4 & GERMANY & 34 \\
\hline 5 & CANADA & 722 & 5 & NETHERLANDS & 31 \\
\hline 6 & FRANCE & 678 & 6 & UK & 29 \\
\hline 7 & SOUTH KOREA & 529 & 7 & FRANCE & 22 \\
\hline 8 & AUSTRALIA & 506 & 8 & THAILAND & 14 \\
\hline & RUSSIA & 504 & 9 & CANADA & 13 \\
\hline 10 & ITALY & 474 & 10 & SWITZERLAND & 10 \\
\hline \multicolumn{6}{|c|}{2007} \\
\hline Rank & CHINA (largest & \multicolumn{2}{|r|}{ Rank } & \multicolumn{2}{|c|}{ INDONESIA (smallest output) } \\
\hline & total output & 98957 & - & total output & 817 \\
\hline 1 & USA & 8971 & 1 & JAPAN & 174 \\
\hline 2 & JAPAN & 2821 & 2 & USA & 148 \\
\hline 3 & UK & 2147 & 3 & AUSTRALIA & 115 \\
\hline 4 & GERMANY & 1822 & 4 & NETHERLANDS & 93 \\
\hline 5 & CANADA & 1719 & 5 & UK & 62 \\
\hline 6 & AUSTRALIA & 1630 & 6 & GERMANY & 48 \\
\hline 7 & FRANCE & 1113 & 7 & THAILAND & 48 \\
\hline & SOUTH KOREA & 1062 & 8 & ITALY & 36 \\
\hline & SINGAPORE & 1003 & 9 & SOUTH KOREA & 35 \\
\hline 10 & TAIWAN & 694 & 10 & MALAYSIA & 33 \\
\hline
\end{tabular}

